\title{
Finances and Well-Being: A Dynamic Equilibrium Model of Resources
}

\author{
Marjan J. Gorgievski-Duijvesteijn \\ Erasmus University Rotterdam and Utrecht \\ University
}

\author{
Arnold B. Bakker, Wilmar B. Schaufeli, \\ and Peter G. M. van der Heijden \\ Utrecht University
}

\begin{abstract}
This study of 513 Dutch farmers tested a dynamic equilibrium model of resources (an extension of the conservation of resources theory; S. E. Hobfoll, 1989, 1998, 2001). With structural equation modeling, the advantages of a 3-wave longitudinal design were comprehensively used, such as addressing bidirectional causal effects and within-individual vs. between-individual change. This allowed for a careful analysis of the management function of resources in the stress process. Results showed that well-being had stronger within-person stability than finances. Increased levels of financial problems temporarily increased psychological distress but not self-reported illness. Conversely, farmers with higher stable baselines of psychological distress also had higher baselines of self-reported illness and experienced more negative changes in their financial situation.
\end{abstract}

Several studies have shown that most life events have only a temporary impact on indicators of subjective well-being, such as measures of satisfaction (Cummins, 2000; Diener, 2000; Heady \& Wearing, 1989; Suh, Diener, \& Fujita, 1996) and mental health (Duncan-Jones, Fergusson, Ormel, \& Horwood, 1990). After some time, people generally recover, and their well-being tends to revert to a particular set point, or traitlike baseline (Stones, Hadjistavropoulos, Tuuko, \& Kozma, 1995). Even in the face of severe trauma, most victims appear to recover within 2 years, showing no long-term, chronic symptomatology (e.g., King, King, Keane, Fairbank, \& Adams, 1998). Additional research has shown that levels of

Marjan J. Gorgievski-Duijvesteijn, Institute of Psychology, Erasmus University Rotterdam, Rotterdam, the Netherlands, and Department of Social and Organizational Psychology and Research Institute Psychology and Health, Utrecht University, Utrecht, the Netherlands; Arnold B. Bakker and Wilmar B. Schaufeli, Department of Social and Organizational Psychology and Research Institute Psychology and Health, Utrecht University; Peter G. M. van der Heijden, Department of Methodology and Statistics, Utrecht University.

This research project was conducted in cooperation with Hennie van der Veen from the Dutch Agricultural Economics Research Institute, to whom we express our gratitude. We also thank Joop Hox for his valuable help with analyzing the data and Evelina Ascalon and Joy Oliver for correcting our spelling and grammar.

Correspondence concerning this article should be addressed to Marjan Gorgievski-Duijvesteijn, Erasmus University Rotterdam, Institute of Psychology J5-37, P.O. Box 1738, NL-3000 DR, The Netherlands. E-mail: gorgievski@ fsw.eur.nl life event exposure may also be stable across individuals (Heady \& Wearing, 1989; Ormel \& Wohlfahrt, 1991; Suh et al., 1996). So, it seems that a dynamic equilibrium keeps individuals functioning on a characteristic baseline level. To date, few attempts have been made to incorporate a dynamic equilibrium perspective into occupational health research.

The present three-wave longitudinal study aims to expand the knowledge derived from previous research by integrating the dynamic equilibrium model (Duncan-Jones et al., 1990; Heady \& Wearing, 1989; Ormel \& Schaufeli, 1991) into a motivational stress theory, namely the conservation of resources (COR) theory (Hobfoll, 1988, 1998, 2001). Postulating a dynamic equilibrium model of resources, this study provides a deeper understanding of how resources are being managed to keep them stable or increasing.

\section{Theoretical Approach: The Dynamic Equilibrium Model of Resources}

On the basis of COR theory, we assert that people strive to build, protect, and retain their resources (Hobfoll, 1988, 1998, 2001). Resources are those objects, personal characteristics, social circumstances, energies, and conditions that are valued and sought after and that aid the requirement of other resources. COR theory predicts that, when confronted with an opportunity to achieve resources or with a (potential) loss of their resources, people will be motivated to obtain, maintain, or retain these resources by investing other resources they possess. 
If this does not lead to the expected outcome, individuals will experience distress and may consequently develop mental and physical health problems. Thus, this means a decrease in mental and physical health resources.

In addition, following the dynamic equilibrium model of Heady and Wearing (1989; see also Duncan-Jones et al., 1990; Ormel \& Schaufeli, 1991), we assert that resources have a stable, traitlike component (thereby, they are stable within persons) and a variable, statelike component. External events, socalled change agents, may cause changes in the levels of resources people possess. For example, a person whose car is stolen suffers material loss and possibly also a loss of personal resources, such as a diminished sense of control and impaired well-being. However, these disruptions are expected to be relatively short lived. Internal, adaptive processes, also referred to as homeostatic processes, will cause resource levels to return to a characteristic traitlike baseline, even if the objective situation has changed permanently (see Figure 1). The stronger the internal processes

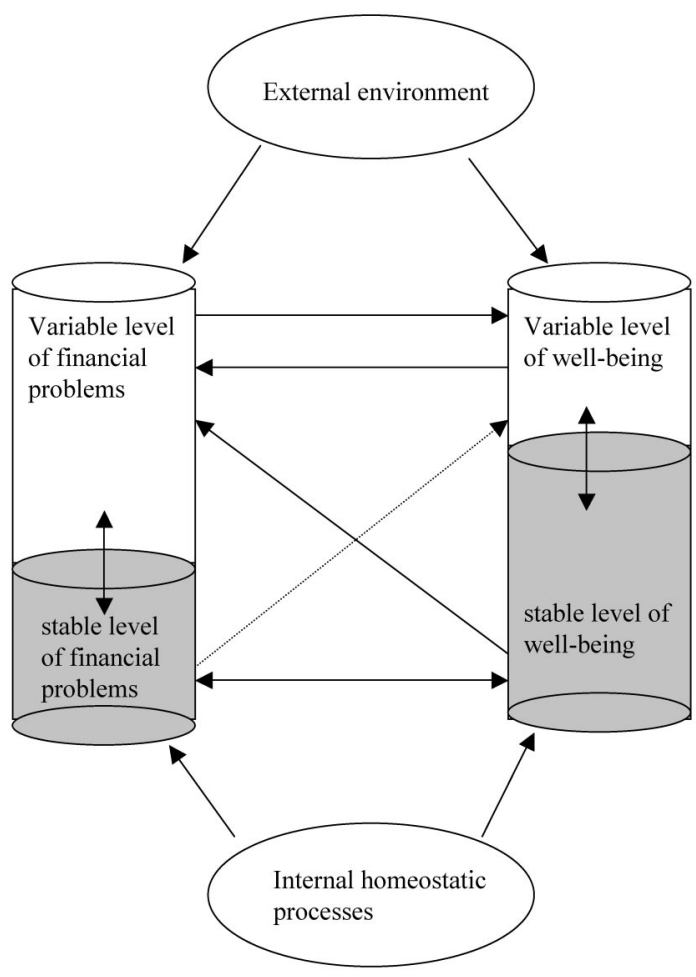

Figure 1. Dynamic equilibrium model of finances and well-being. that maintain homeostasis of a particular resource, the smaller the potential influence of change agents, and thus the larger the stable component of that resource. This stability-and-change model has been tested for psychological distress, but so far only occasionally has the model been extended to include other variables as well (e.g., Schaufeli, 1997).

Reviewing the literature, Hobfoll (2002) noted that research on homeostatic processes (adaptation) to date has mainly used a key resource approach. Several personality characteristics (neuroticism, extraversion, and openness to experience) have been identified as key resources to homeostasis in both wellbeing and life event exposure (e.g., Duncan-Jones et al., 1990; Heady \& Wearing, 1989; Ormel \& Schaufeli, 1991; Ormel \& Wohlfahrt, 1991). According to this approach, people's characteristic symptom levels are the result of stable attributes, such as personality, prolonged stress factors, persistent physical disorders or disabilities, and chronic psychopathological disorders of somatic origin (Depue \& Monroe, 1985). Additionally, several authors have emphasized that cognitive processes aimed at maintaining personal resources, such as self-esteem, optimism, and control, are important for restoring well-being (Cummins \& Nistico, 2002; Taylor \& Brown, 1988, 1994). Finally, exclusively related to well-being, homeostasis in resource levels can be referred to as a person's constitution. This can be attributed to lower order, physiological feedback mechanisms (Lovallo, 1997).

In contrast, on the basis of COR theory (Hobfoll, 1988, 2001, 2002), we adopt a broader, more dynamic view concerning homeostasis. According to COR theory, disruptions in resource levels are restored, because individuals are motivated to increase, maintain, or retain resources by investing other resources they possess. People may use a wide array of strategies to do so, some of which are faster and more effective than others. They not only include mechanisms involving cognitive processes, such as positive cognitive bias (Cummins \& Nistico, 2002) or selfenhancing cognitions (Taylor \& Brown, 1988, 1994), but also include behavioral processes, or actions, which may be accompanied by (secondary) resource losses or gains. Such cognitive and behavioral feedback processes are less fine-tuned and much slower than the lower order feedback mechanisms that apply to well-being resources (Lovallo, 1997). For this reason, disruptions in the levels of resources to which only higher order feedback mechanisms apply are expected to be larger and to have a longer duration than disruptions in well-being resources. 
The present study expands the knowledge derived from previous research by examining the bidirectional longitudinal relationships between two resources that in Western culture are broadly recognized as important (Hobfoll, 1998), namely finances and well-being. Following the current trend of using multidimensional measures of well-being (see, e.g., Van Horn, Taris, Schaufeli \& Schreurs, 2004), we have operationalized it as psychological distress and self-reported illness. Despite their commonsense appeal, finances have received relatively little attention from occupational stress researchers. On the basis of our general theoretical framework, we first addressed the extent to which financial resources, psychological distress, and self-reported illness indeed have stable baseline levels. Second, we investigated bidirectional causal relationships between finances and well-being, taking stable baselines and variable levels (deviations from the baseline) of all resources into account.

The research model is tested among the self-employed, namely Dutch farmers, to whom the relationship between finances and well-being is of particular concern. For self-employed individuals, financial means are not only important for the fulfillment of personal or family needs but also relate to the future of the business and therefore their means of subsistence. During the past decades, political and societal developments, such as changing policies of the European Union, growing global competition, and increasing consumer demands, have required dramatic shifts in the nature of farming and have made financial problems a major concern by increasing production costs and decreasing returns on agricultural products. Additionally, the agricultural community in Europe has been facing calamities such as floods, diseases in crops, and animal diseases (e.g., BSE, pigs flu, foot-and-mouth disease). Consequently, the number of agricultural businesses has steadily declined (Vidal, 2000). Agriculture in the Netherlands followed the same trends (Landbouw Economisch Instituut, 2000). For farmers, having to quit the business not only means losing valued property but also means losing the most important source of income and farming as a way of life. Not surprisingly, foreclosure of the farm has been found to have a great impact on the mental and physical health of the farmers concerned (Rosenblatt, 1990).

\section{Stability of Finances and Well-Being}

Little is known empirically about the extent to which finances, psychological distress, and self-reported illness differ with respect to the proportion of their stable and variable levels. Our study is the first to explore the extent to which a dynamic equilibrium exists for self-reported illness and financial problems. Baselines have been shown to explain about two thirds of the variance in psychological distress among a variety of samples, irrespective of the number of measurement occasions and measurement instruments (see Duncan-Jones et al., 1990; Ormel \& Schaufeli, 1991). Concerning self-reported illness, because it partly reflects people's physical health status and because it strongly relates to personality variables, such as negative affectivity (e.g., Watson \& Pennebaker, 1989), self-reported illness can be expected to have a large stable component as well. In contrast, we expect financial resources, in particular liquid financial means, to be less stable than wellbeing (Hypothesis 1). First, lower order physiological mechanisms do not directly influence finances. Second, liquid financial means, such as money in a current bank account, can be considered as "energy," a resource with important exchange value (see Hobfoll, 1988). When confronted with external demands, individuals are expected to invest their energy resources more readily than other resources. Finally, in contrast to well-being, financial means are generally used up when invested.

\section{The Bidirectional Relationship Between Finances and Well-Being}

We expect that external events primarily depleting one resource will indirectly lead to the depletion of other resources over time. For example, after job loss, a person may need to spend time and money to upgrade his or her qualifications to find another job. If this does not lead to the expected outcome, the person might feel helpless and become depressed, which, in turn, may lead to medical costs, thus further depleting financial resources. This means that we assume bidirectional relationships exist between stressors and strains. In occupational health research, relationships leading from stressors (e.g., financial hardship) to well-being are found more often than reversed causal relationships (Zapf, Dormann, \& Frese, 1996). One of the reasons may be that previously researched groups could influence the occurrence of job stressors only to a limited extent. This is not likely to be the case in our study, because it addressed self-employed individuals running a family farm in the Netherlands. Compared with employees on payroll, the self-employed can be assumed to substantially influence their business productivity, 
and hence their financial situation, as they provide most of the labor themselves and make all managerial decisions (see Gasson \& Errington, 1993). Indeed, a 10-year follow-up study among almost 100 Dutch dairy-farm couples (Gorgievski-Duijvesteijn, Giesen, \& Bakker, 2000) showed that farmers' mental and physical health complaints predicted farm couples' financial problems 10 years later, whereas no longterm effect was found for financial problems on wellbeing. In contrast, a study among nearly 400 rural families in Iowa showed a causal effect of poor finances on husbands' and wives' mental health complaints over a period of 3 years but no reversed causal effect (Lorenz, Conger, Montague, \& Wickrama, 1993; Swisher, Elder, Lorenz, \& Conger, 1998). These inconclusive results have led to the suggestion (Gorgievski-Duijvesteijn et al., 2000) that, compared with the effect of stressors on well-being, (a) the reversed causal effect may particularly occur in the long term and (b) the causal and reversed causal effects are affected differentially by stability of the environment. Our study addresses the latter possibility in greater detail.

\section{A Differential Effect of a Stable Environment on Causal and Reversed Causal Relationships}

We propose that two mechanisms underlie the reciprocal effects between finances and well-being, which are differentially influenced by stability of the environment. In the first process, in which financial problems are expected to impair well-being (the direct stress chain), change plays a central role (see Hobfoll, 1988, 1998, 2001). A net loss of resources, real or anticipated, is expected to cause distress and health complaints. Enduring financial hardship is not expected to impair well-being, unless it is accompanied by resource loss of some kind. Resources may be lost as a result of active attempts to solve financial problems, such as reduced solvency after taking an extra loan (Mulder, 1994). Furthermore, less tangible resources may be lost, such as a sense of mastery and self-esteem (Pearlin, Lieberman, Menaghan, \& Mullan, 1981), social support, and quality of interpersonal interactions (e.g., Vinokur, Price, \& Caplan, 1996). On the basis of this assumption, we formulated Hypothesis 2 in terms of the dynamic equilibrium model of resources: The more financial problems individuals face on top of their (normal) baseline level of financial problems, the more wellbeing will deviate negatively from its baseline (i.e., variable levels of financial problems predict variable levels of well-being). Only under these conditions do we expect people to feel distressed and motivated to solve their financial problems.

In the same vein, external influences may primarily affect well-being, such as health hazards to farmers related to working with pesticides. As illness can render individuals incapable of working or confront them with high medical costs, impaired health may affect their financial situation. However, we expect another process to be more important, namely the resource management process. This refers to key resources that help to accumulate other resources and buffer against resource loss caused by external threats (Hobfoll, 2002). We consider the traitlike baseline of well-being to be such a key resource. Overall, individuals feeling healthier are likely to get more work done in the same amount of time. Additionally, people with better mental health may also be better able to use opportunities and to handle adversity. For the majority of the self-employed, the ongoing impact of chronic poor well-being is expected to be more important than the potential negative impact of a sudden health-related event, such as catching the flu. So, Hypothesis 3 is as follows: The stable baseline rather than the variable levels of psychological distress and self-reported illness influence both the baseline and variable levels of financial problems.

Empirical evidence regarding these predictions is scarce, reflecting the paucity of longitudinal studies on within-individual change in general. Regarding negative effects of increased financial problems on well-being as compared with an enduring poor financial situation, the body of evidence is growing. The earliest evidence comes from studies addressing satisfaction and happiness. For example, one classic study has shown that winning a lottery only had a temporary positive effect on satisfaction (Brickman, Coates, \& Janoff-Bulman, 1978). Additionally, several other studies showed that only recent changes in pay predicted job satisfaction (Clark, 1998) and satisfaction with life (Saris, 2001). Based on COR theory, the primacy of resource loss over resource gain or a stable lack of resources has been proven among a variety of samples (e.g., Freedy, Saladin, Kilpatrick, Resnick, \& Saunders, 1994; Holahan, Holahan, Moos, \& Cronkite, 2000; Holahan, Moos, Holahan, \& Cronkite, 1999; Norris \& Kaniasty, 1996). Concerning a stress effect of poor finances, recent evidence has shown that acute economic loss had a much greater impact on depression than the chronic state of poverty among inner-city women. Moreover, the impact of chronic conditions of poverty worked 
almost exclusively through material loss (Ennis, Hobfoll, \& Schröder, 2000; Hobfoll, Johnson, Ennis, \& Jackson, 2003). In contrast, another study showed that financial loss following a technological disaster (i.e., the Exxon Valdez oil spill) did not predict anxiety, depression, and posttraumatic stress disorder among commercial fishers, after controlling for diminished social networks and impaired physical health (Arata, Picou, Johnson, \& McNally, 2000). Regarding the reversed causal relationship, to the best of our knowledge, no comparisons have been made concerning the effect of baseline versus variable levels of psychological distress and self-reported illness on finances.

\section{Method}

\section{Participants and Procedure}

A total of 688 Dutch farmers and horticulturists participating in the Farm Accountancy Data Network (Van Dijk, Groot, Lodder, \& Vrolijk, 1998) of the Dutch Agricultural Economics Research Institute were asked to fill out questionnaires during spring 1998, 1999, and 2000. There were 513 participants: $513(75 \%)$ in the first wave (Time 1 [T1]), $405(59 \%)$ in the second wave (Time 2 [T2]), and 361 $(52 \%)$ in the third wave (Time 3 [T3]). Dropouts were included in the analyses, using missing-value analyses (see below). Farms owned by more than one person who were not family members were excluded. Participants were 473 men and 29 women between 21 and 65 years of age, with an average and median of 44 years at the start of the study $(S D=9.71)$. Mean farm size of the sample was 114 European size units $(E S U s)^{1}(S D=78)$. Very small farms (less than 50 ESUs) were slightly underrepresented, whereas large farms (over 80 ESUs) were slightly overrepresented.

Farmers who refused to participate in our study did not differ significantly from those who participated with respect to business features (size, number of people working at the farm, and agricultural branch). Furthermore, farmers participating in all three data waves $(N=314)$ did not differ significantly from those who dropped out with regard to business features (size, number of hours worked at the farm, financial situation), family features (family size, youngest child's age), and farmers' characteristics (age, psychological distress, self-reported illness). Only 5\% of attrition was caused by respondents leaving the population $(n=36)$.

\section{Measures}

Perceived financial problems were measured with an eight-item scale, based on Giesen (1991) and Mulder (1994). The items were introduced with the sentence: "Lately, how often has it occurred that ...." followed by, for example, "you did not have enough money to make ends meet?" "were unable to pay the bills on time?" and "you had to work with worn-out machinery, because you lacked financial means to replace them?" Answers ranged from $1=$ never or rarely to $5=$ very often. Internal consistency (Cronbach's alpha) was .84 for $1998, .87$ for 1999 , and .85 for 2000.

Psychological distress was measured with a Dutch 12item version of the General Health Questionnaire (Goldberg, 1972), which measures nonspecific psychiatric illness and discriminates between "cases" and "noncases" in the normal population. Examples are as follows: "Lately, have you felt unhappy and depressed?" "Lately, have you felt capable of making decisions about things?" (reverse coded), and "Lately, have you been thinking of yourself as a worthless person?" Respondents were asked to indicate the extent to which they had experienced any of these complaints during the preceding few weeks. Answer categories ranged from $1=$ less than usual to $4=$ much more than usual. Cronbach's alpha of the scale was .86 for each of the 3 years.

Self-reported illness was measured with a 21-item checklist, the Dutch Health Perception Questionnaire (Vragenlijst Onderzoek Ervaren Gezondheid; Dirken, 1967). Respondents could indicate whether they had experienced health problems during the preceding few weeks, such as headaches, back pains, stomach complaints, fatigue, dizziness, and cardiac complaints $(0=$ no, $1=$ yes $)$. Kuder-Richardson 20 (KR20) was .83 for $1998, .85$ for 1999 , and .84 for 2000. Compared with psychological distress, self-reported illness related strongly to other health status indicators, such as number of physician visits $\left(R^{2}\right.$ ranged between .21 and .31 as compared with .02 and .12 for psychological distress) and medicine use ( $R^{2}$ ranged between .32 and .35 as compared with .02 and .15), indicating it had a clear healthrelated component.

\section{Strategy of Analysis}

Hypotheses were tested using structural equation modeling (SEM) with the AMOS software package (Arbuckle, 1997). The full information maximum-likelihood method was used to correct for missing values. Prior to the SEM analyses, we performed a natural logarithmic transformation on the left-skewed raw scores of financial problems and psychological distress, leading to skewness and kurtosis of below 1.5. To examine how closely competing models fit to the data, we calculated (see $\mathrm{Hu} \&$ Bentler, 1999) the chisquare likelihood ratio, Bonnet's nonnormed fit index (NNFI), and the root-mean-square error of approximation (RMSEA). The NNFI should be larger than .95, and the RMSEA should be below .05. Because the time intervals between $\mathrm{T} 1$ and $\mathrm{T} 2$ and between $\mathrm{T} 2$ and $\mathrm{T} 3$ are equal, all identical relationships were constrained to be equal across measurement moments for reasons of parsimony.

To obtain an optimal basis for our analyses, we first fitted a measurement model (the two-step approach of Anderson \& Gerbing, 1988). Psychological distress and self-reported illness were strongly related (see Table 1), which may

\footnotetext{
${ }^{1}$ European size units (ESUs) are defined as units gross standard balance (GSB) corrected for price developments in Europe (Landbouw Economisch Instituut, 2000). ESUs are calculated by dividing the GSB by a norm factor specified by the European Union. ESUs allow a comparison of the size of businesses operating in different branches.
} 
Table 1

Means, Standard Deviations, and Correlations of the Observed Variables, $N=513$

\begin{tabular}{|c|c|c|c|c|c|c|c|c|c|c|c|c|c|c|c|c|c|c|c|c|}
\hline \multirow[b]{2}{*}{ Variable } & \multirow[b]{2}{*}{$M$} & \multirow[b]{2}{*}{$S D$} & \multicolumn{6}{|c|}{ Time 1} & \multicolumn{6}{|c|}{ Time 2} & \multicolumn{6}{|c|}{ Time 3} \\
\hline & & & 1 & 2 & 3 & 4 & 5 & 6 & 7 & 8 & 9 & 10 & 11 & 12 & 13 & 14 & 15 & 16 & 17 & 18 \\
\hline \multicolumn{21}{|l|}{ Time 1} \\
\hline 1. Financial problems 1 & 0.69 & 0.36 & - & & & & & & & & & & & & & & & & & \\
\hline 2. Financial problems 2 & 0.23 & 0.33 & .70 & - & & & & & & & & & & & & & & & & \\
\hline 3. Psychological distress 1 & 0.64 & 0.19 & .24 & .25 & - & & & & & & & & & & & & & & & \\
\hline 4. Psychological distress 2 & 0.55 & 0.20 & .21 & .23 & .72 & - & & & & & & & & & & & & & & \\
\hline 5. Self-reported illness 1 & 1.41 & 1.66 & .14 & .14 & .33 & .27 & - & & & & & & & & & & & & & \\
\hline 6. Self-reported illness 2 & 1.72 & 2.03 & .20 & .18 & .52 & .44 & .66 & - & & & & & & & & & & & & \\
\hline \multicolumn{21}{|l|}{ Time 2} \\
\hline 7. Financial problems 1 & 0.73 & 0.34 & .66 & .53 & .23 & .17 & .10 & .16 & - & & & & & & & & & & & \\
\hline 8. Financial problems 2 & 0.28 & 0.36 & .49 & .63 & .24 & .20 & .09 & .18 & .69 & - & & & & & & & & & & \\
\hline 9. Psychological distress 1 & 0.64 & 0.17 & .18 & .21 & .45 & .33 & .26 & .35 & .28 & .36 & - & & & & & & & & & \\
\hline 10. Psychological distress 2 & 0.56 & 0.19 & .10 & .17 & .38 & .42 & .21 & .32 & .23 & .34 & .68 & - & & & & & & & & \\
\hline 11. Self-reported illness 1 & 1.36 & 1.65 & .14 & .16 & .34 & .30 & .73 & .63 & .10 & .16 & .37 & .35 & - & & & & & & & \\
\hline 12. Self-reported illness 2 & 1.68 & 2.07 & .19 & .21 & .45 & .35 & .53 & .75 & .16 & .22 & .48 & .46 & .67 & - & & & & & & \\
\hline \multicolumn{21}{|l|}{ Time 3} \\
\hline 13. Financial problems 1 & 0.73 & 0.35 & .58 & .45 & .29 & .22 & .14 & .22 & .72 & .60 & .38 & .31 & .18 & .24 & - & & & & & \\
\hline 14. Financial problems 2 & 0.27 & 0.34 & .43 & .55 & .33 & .32 & .13 & .22 & .54 & .72 & .33 & .29 & .20 & .24 & .68 & - & & & & \\
\hline 15. Psychological distress 1 & 0.63 & 0.17 & .12 & .10 & .51 & .40 & .26 & .34 & .21 & .19 & .44 & .38 & .32 & .41 & .28 & .32 & - & & & \\
\hline 16. Psychological distress 2 & 0.58 & 0.18 & .06 & .12 & .43 & .44 & .23 & .37 & .14 & .15 & .32 & .43 & .32 & .38 & .22 & .26 & .70 & - & & \\
\hline 17. Self-reported illness 1 & 1.44 & 1.60 & .15 & .14 & .31 & .27 & .67 & .56 & .11 & .11 & .29 & .30 & .78 & .59 & .15 & .16 & .33 & .36 & - & \\
\hline 18. Self-reported illness 2 & 1.84 & 2.13 & .19 & .18 & .37 & .30 & .54 & .68 & .13 & .16 & .38 & .34 & .63 & .71 & .24 & .23 & .49 & .48 & .69 & - \\
\hline
\end{tabular}

Note. Scores of financial problems (In-transformed) range from 0 to 1.61, of psychological distress (ln-transformed) range from 0 to 1.39 , and of self-reported illness range from 0 to 10 (1st indicator) or 0 to 11 (2nd indicator). 
reflect both actual bidirectional relationships (e.g., Lovallo, 1997) and the influence of a third variable, such as negative affectivity (e.g., Watson \& Pennebaker, 1989). We tested whether the scales might have measured one underlying construct, which was not our intention. Confirmatory factor analysis showed this was not the case. A two-factor model fitted much better to the data than a one-factor model: for $1998, \Delta \chi^{2}(1)=540.00, p<.001$; for $1999, \Delta \chi^{2}(1)=$ $495.40, p<.001$; and for $2000, \Delta \chi^{2}(1)=443,90, p<.001$; hence, the scales were not collapsed into one symptomatology variable. Instead, to correct for measurement error, we randomly split each of the scales measuring financial problems, psychological distress, and self-reported illness in 1998, 1999, and 2000 into two reliable halves and used them as separate indicators of the latent variables. The model additionally contained covariances between all latent variables. Significant covariances between error terms of identical measures over time were also modeled, as these are likely caused by systematic error not of theoretical interest, such as response bias (Fergusson \& Horwood, 1988). The resulting measurement model fits well to the data, $\chi^{2}(93, N=513)=105.37, p=.18, \mathrm{NNFI}=1.00$, RMSEA $=.02$

Subsequently, we tested the dynamic equilibrium model of finances and well-being. This model split financial problems, psychological distress, and self-reported illness each into one factor representing the stable baseline levels over time, and three factors representing the variable levels at $\mathrm{T} 1$, T2, and T3, respectively (see Figure 2; Duncan-Jones et al., 1990; Ormel \& Schaufeli, 1991). This stability-and-change model makes two assumptions: First, the baseline level of financial problems (psychological distress and self-reported illness) plus the variable level at one specific point in time explain all variance in financial problems (psychological distress and self-reported illness) at that point; second, by definition, external events are assumed not to influence the baseline resource levels. Consequently, the baseline resource levels are not treated as dependent variables in the dynamic equilibrium model.

\section{Results}

\section{Descriptive Statistics}

Table 1 shows descriptive statistics of the observed variables. The mean scores on all scales were rather low. The general linear model repeated measures procedure showed that scores on the nontransformed eight-item financial problems scale increased slightly from $1.74(S D=0.64)$ in 1998 to $1.83(S D=0.67)$ in 1999 and $1.83(S D=0.67)$ in $2000, F(2,1024)=$ $12.99, p<.001$.

\section{Testing the Dynamic Equilibrium Model of Resources}

To test whether well-being is more stable across time than finances (Hypothesis 1), we fitted a dynamic equilibrium model to the data for each of the three variables separately (see Figure 2). The fit of the model for psychological distress was $\chi^{2}(6, N=$ $513)=2.14, p=.91, \mathrm{NNFI}=1.00, \mathrm{RMSEA}=.00$;

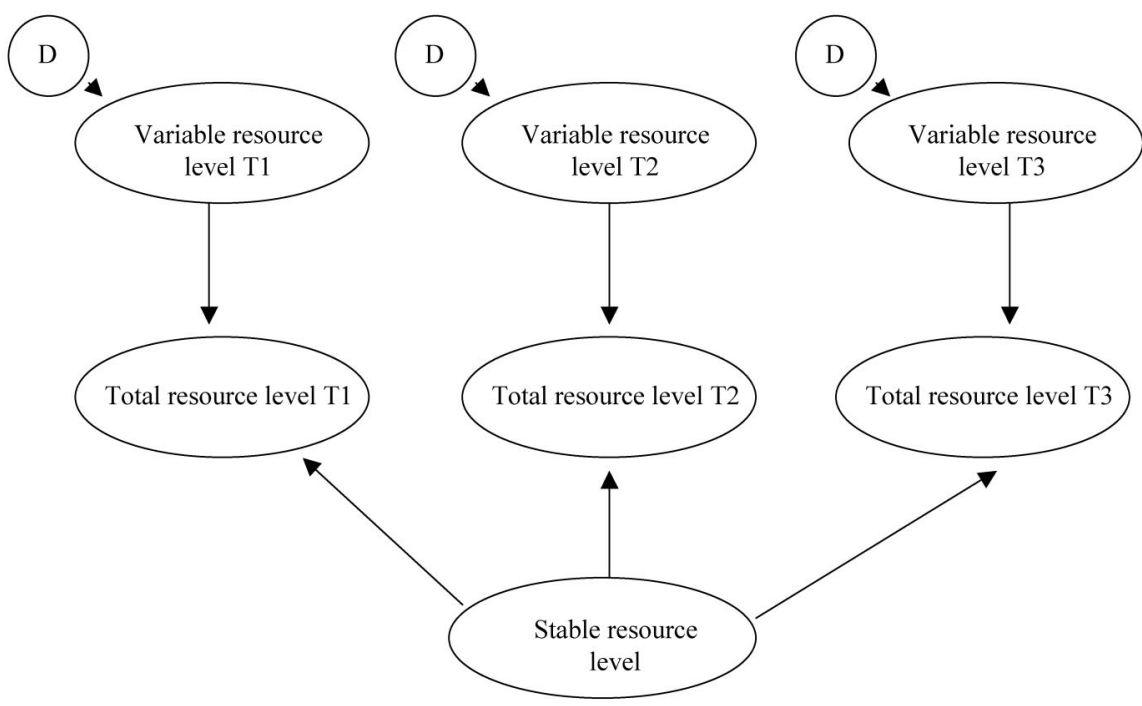

Figure 2. The stability-and-change model (cf. Duncan Jones et al., 1990, and Ormel \& Schaufeli, 1991). D = residual, unexplained variance; $\mathrm{T} 1=$ Time $1 ; \mathrm{T} 2=$ Time 2 ; $\mathrm{T} 3=$ Time 3. 
for self-reported illness $\chi^{2}(5, N=513)=5.70, p=$ $.34, \mathrm{NNFI}=1.00, \mathrm{RMSEA}=.02$; and for financial problems $\chi^{2}(5, N=513)=4.76, p=.45$, NNFI $=$ 1.00, RMSEA $=.00$. In support of Hypothesis 1 , the traitlike baseline accounted for $48 \%-56 \%$ of total variance in psychological distress, and $62 \%-71 \%$ of variance in self-reported illness, whereas for financial problems, these percentages ranged between $14 \%$ and $18 \%$. These findings clearly indicate that wellbeing (indicated by psychological distress and selfreported illness) is more stable than financial problems.

The dynamic equilibrium models demonstrated strong autoregressions between variable levels of self-reported illness and financial problems, indicating that another form of stability, namely experienced health (or financial) problems, accounted for by external events at one point in time made people vulnerable for experiencing health (or financial) prob- lems 1 year later. In contrast, the autoregressive paths between the variable levels of psychological distress were not significant, which indicates that stability of mental health was exclusively the result of homeostatic psychological processes.

Furthermore, to test Hypotheses 2 and 3, we modeled relationships between the baseline and variable levels of each of the variables included in our study (financial problems, psychological distress, and selfreported illness). Figure 3 shows the final dynamic equilibrium model of resources, which fits very well to the data: $\chi^{2}(118, N=513)=132.42, p=.17$, $\mathrm{NNFI}=1.00$, RMSEA $=.02$. The first interesting finding concerns the baselines. As expected, the baselines of psychological distress and self-reported illness are strongly related $(B=.10, S E=.02, p<$ $.001)$. However, no significant relationships were found between the baselines of psychological distress and self-reported illness, and between baseline levels

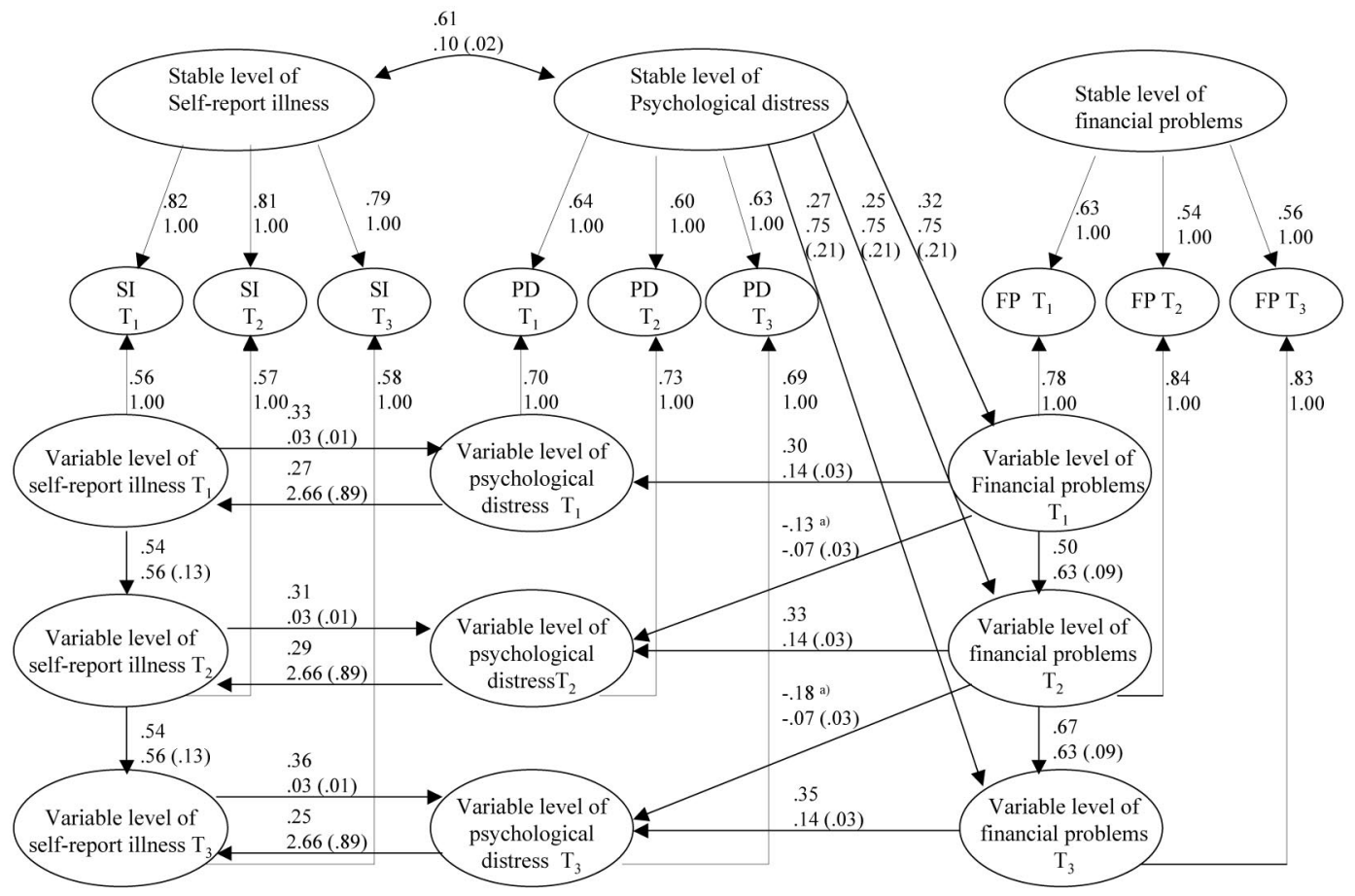

Figure 3. Final dynamic equilibrium model of finances and well-being: $\chi^{2}(118, N=513)=$ $132.42, p=.17$; nonnormed fit index $=1.00$; root-mean-square error of approximation $=.02$. Time $1(\mathrm{~T} 1)=1998$; Time $2(\mathrm{~T} 2)=1999$; Time $3(\mathrm{~T} 3)=2000$; SI $=$ total levels of self-reported illness; $\mathrm{PD}=$ total levels of psychological distress; FP = total levels of financial problems. Superscript a) denotes that this suppressor effect indicates a significant effect of current minus previous financial problems. 
of financial problems. This suggests that different mechanisms may restore the equilibrium of finances as compared with subjective well-being.

Second, in line with Hypothesis 2, the dynamic equilibrium model of resources showed that only the variable levels of financial problems and not the baseline predicted variable levels of psychological distress. To test the extent to which this effect was due to actual changes, we modeled a possible suppressor effect of financial problems that had been experienced in the preceding year (Saris, 2001). ${ }^{2}$ This suppressor effect was indeed significant $(B=$ $-.07, S E=.03, p<.05)$, indicating that the consequences of financial problems for farmers' well-being were stronger for farmers whose financial situation had deteriorated. In addition, more enduring financial problems influenced psychological distress equally strong $(B=.07, S E=.03, p<.05)$, provided they deviated from the baseline. Setting the effect of enduring financial problems equal to zero deteriorated the fit significantly: $\Delta \chi^{2}(1)=4.10, p<.001$.

No relationship was found between finances and self-reported illness. However, deviations in levels of psychological distress and self-reported illness were mutually related, which means that financial problems may lead to changes in health perception through changes in psychological distress.

Third, Hypothesis 3 was partially supported as well. Baseline psychological distress levels, but not deviations in psychological distress, predicted financial problems. This was not because individuals suffering chronic psychological distress had higher baselines of financial problems but because chronic psychological distress affected the variable levels of financial problems at each point in time with the same magnitude $(B=.75, S E=.21, p<.001)$. Chronic psychological distress explained between $2 \%$ and $3 \%$ of the variance in variable levels of financial problems, on top of previous variable levels of financial problems. Again, no effect was found for self-reported illness.

\section{Discussion}

Postulating a dynamic equilibrium model of resources based on COR theory (Hobfoll, 1988, 1998, 2001 ) and the dynamic equilibrium model (DuncanJones et al., 1990; Heady \& Wearing, 1989; Ormel \& Schaufeli, 1991), this study set out to increase our understanding of the management function of resources proposed in COR theory. We hypothesized that all resources have stable, traitlike baseline levels. External events may cause fluctuations in these re- source levels, but these are expected to be rather short lived, because homeostatic mechanisms cause resource levels to return to their original baselines. Following COR theory, we theorized that these homeostatic mechanisms include not only biological or cognitive processes but also people's actions aimed at actively restoring resource levels by investing other resources they possess (Hobfoll, 1988, 2001). Our results showed that testing a dynamic equilibrium model of resources is relevant for disentangling cause-and-effect relationships between material resources and well-being.

We found that both finances and well-being have stable within-person baselines. Concerning psychological distress, our results are strikingly similar to those of previous studies (Duncan-Jones et al., 1990; Ormel \& Schaufeli, 1991). In support of our first hypothesis, the baseline of financial problems explained less variance in total levels of financial problems, such as not having enough money to make ends meet ( $14 \%$ to $18 \%)$, than baseline psychological distress in total levels of psychological distress (48\% to $56 \%)$ and baseline self-reported illness in total levels of self-reported illness (62\% to $71 \%$ ). This indicates that external events influenced finances to a larger extent than well-being. In addition, the finding that the baselines of finances and well-being were unrelated underscores the presumption that different homeostatic processes cause baselines to remain stable for finances and well-being. Most important, wellbeing is influenced to a large extent by physiological feedback mechanisms that are more refined and much faster than higher order feedback mechanisms involving cognition and behavior (Lovallo, 1997), which are typically more relevant for finances. A study by Kozma, Stone, and Stones (2000) revealed that stability in subjective well-being is mainly due to personality and affective styles (internal processes) and, to a much lesser extent, to a stable environment. In contrast, concerning material resources, environmental stability may be a relatively important explanation for the stable baseline levels.

Another possibility is that our research population (i.e., farmers) faced more threats to their finances

\footnotetext{
${ }^{2}$ Mathematically, it can be proven that a significant effect of a deteriorating financial situation manifests itself as a suppressor effect of previous financial problems in a threewave three-variables model. Equation 1 represents the effect of financial problems at Time $2\left(\mathrm{FP}_{\mathrm{t} 2}\right)$ plus the effect of changes in financial problems as compared with a previous point in time $\left(\mathrm{FP}_{\mathrm{T} 2}-\mathrm{FP}_{\mathrm{T} 1}\right)$ on self-reported illness at Time $2\left(\mathrm{SI}_{\mathrm{T} 2}\right)$ :
} 
than to their well-being. This explanation does not seem very satisfactory. For instance, previous farm studies have identified many potential health hazards related to working with agricultural machinery, chemicals, and large animals (e.g., Gallagher \& Tierney, 1996). In our sample, $5 \%$ of the farmers were involved in work-related accidents annually. This rate is about 3.5 times higher than for self-employed Dutch people in other industries (Statistics Netherlands, 2000). In addition, Dutch farmers are currently facing many stressors affecting their well-being on top of financial problems. Most important, market developments and governmental policies have demanded dramatic changes in the nature of farming, such as an increase in administrative tasks and a higher workload in general (Gorgievski-Duijvesteijn, 1999).

Note that, although finances had a relatively small stable baseline, financial problems at one point in time did predispose farmers to experiencing financial problems in the near future. This indicates another form of stability: Attempts to change the financial situation need some time to take effect. This was also found for self-reported illness but not for psychological distress.

Variable, statelike levels of financial problems predicted variable levels of psychological distress. This supports the primacy-of-loss principle (Hypothesis 2 ), according to which negative changes in resource levels (loss) lead to more distress than a chronic low resource level (lack). The effect of the variable level of financial problems was even stronger for farmers who had experienced an actual deterioration of their financial situation over the past year. In contrast, stable baseline levels of financial problems did not affect well-being. This means that longer lasting financial difficulties impaired well-being, provided these difficulties deviated from their stable baseline. A plausible explanation may be that in the face of long-term financial problems, people continue to invest (and lose) other resources until the original baseline has been restored. Even though this baseline may still represent rather severe financial problems, people may have found ways to adjust to them that are unrelated to further losses. This assumption is supported by a recent study among inner-city women (Ennis et al., 2000; Hobfoll et al., 2003) that showed that chronic economic hardship only leads to distress through secondary (material) loss. However, for the subpopulation of African American women who are more highly represented in low-income groups, a low income was shown unrelated to its correlates among other groups, such as depression, social support, and mastery, which might indicate that in comparison with other groups of women, their adjustment would be more detached from other life experiences. In other words, they somehow prevented the occurrence of secondary loss.

Another possibility would be that the baseline levels of financial problems were equivalent to an absence of problems. Naturally, when people do not face financial problems, no stress is expected to ensue. Indeed, examination of our data shows that most respondents (87\%) had low mean levels of financial problems over the years $(M=1.71$ on a 5 -point scale, $S D=0.64)$, but the sample also contained a minority of farmers with severe and enduring financial problems, with a maximum of 4.57 .

Financial problems were found to have no direct effect on self-reported illness. Possibly, a whole range of other, more direct factors might have influenced farmers' physical health, such as the workrelated health hazards mentioned before. In addition, outdoor physical work may harden farmers (Bernard \& Krupat, 1994). For this reason, concerning the variable levels of self-reported illness, they may only have reported rather severe health problems that occurred after a long period of exposure to financial problems. The time span of this study may have been too short to capture such an effect. However, variable levels of psychological distress and self-reported illness were mutually related, indicating that disturbances in the financial situation may lead to selfreported illness through increased psychological distress. For example, mental health may influence self-reported illness through physiological responses related to them (Lovallo, 1997).

In line with Hypothesis 3, findings showed a reversed causal effect from well-being to the financial situation. This is in line with the body of evidence showing that strains may lead to job stressors (e.g., Aldwin \& Revenson, 1986; Glickman, Tanaka, \& Chan, 1991; Hamilton, Hoffman, Broman, \& Rauma, 1993; Jonge et al., 2001; Taris, 1999; Taris, Bok, \& Caljé, 1998; Zapf et al., 1996), in the case that people can be expected to actually influence the occurrence of these stressors (Beehr, Jex, Stacy, \& Murray, 2000). Mechanisms explaining these relationships include, for example, impaired performance (e.g., Baron, 1990; Beehr et al., 2000; Motowidlo, Manning, \& Packard, 1986; Trope \& Neter, 1994) and poor social functioning (e.g., Jones \& Fletcher, 1993; Vinokur et al., 1996). Our results showed that chronic psychological distress, as opposed to temporary fluctuations from the baseline, predicted finances. It is interesting that chronic psychological distress pre- 
dicted whether financial problems would deviate more from their stable baseline but not whether farmers had higher baseline levels of financial problems. This contradicts the possibility that the relationship would be an artifact of, for instance, negative answering tendencies related to negative affectivity (Burke, Brief, \& George, 1993). Well-being may indirectly protect individuals against negative influences of the external environment on finances, presumably because they are better able to use financial opportunities or to handle financial risks. As such, well-being is an important resource, which seems to lie at the core of an upward "spiral of gain" (Hobfoll, 2001).

Self-reported illness did not predict financial problems over and above psychological distress. Possibly, it is easier to find ways to adjust to perceived poor physical abilities than to psychological distress. Physical complaints may mainly impair manual labor, which could be taken over by others, whereas psychological distress may affect less tangible abilities that may long go unnoticed, such as motivation and cognitive functioning (Jex, 1998). Hence, for the self-employed, consequences of psychological distress may be far reaching, as it may also affect managerial tasks and decision making (Staw, Sandelands, \& Dutton, 1981).

\section{Study Limitations}

Our study had several limitations. First, it did not provide information on the objective environment. Expanding the dynamic equilibrium model of resources with objective, external events would allow researchers to directly test our assertion that wellbeing helps individuals counteract resource loss when facing external threats, as well as the relative influence of external events as compared with internal homeostatic processes on resource levels. Additionally, a subsequent study could benefit from measuring material and health resources more objectively. As previous studies have shown, selfreported illness may only modestly reflect people's actual health status (Watson \& Pennebaker, 1989). Likewise, even though husbands and wives have been found to strongly agree on the extent to which they experience financial problems (GorgievskiDuijvesteijn et al., 2000), it would still be useful to see how this is anchored in the objective financial situation.

Second, concerning subjective well-being, it would be interesting to include more positive indicators in addition to psychological distress and selfreported illness. As previous studies have shown, variables tend to relate differently to different measures of well-being (Diener, Suh, Lucas, \& Smith, 1999), and findings on the negative side of the stressor-strain continuum might not necessarily extrapolate to the positive side. The process we have described as the direct stress chain resembles the "hedonic treadmill" based on Helson's adaptation theory (for a review, see Frederick \& Loewenstein, 1999), according to which satisfaction gives way to indifference and even dissatisfaction after repeated confrontation with a positive stimulus, and stimuli causing dissatisfaction become affectively neutral after repeated exposure. The hedonic treadmill has received support for positive measures of well-being, such as life satisfaction and happiness. However, it seemed to occur only for some stimuli (e.g., financial gains) but not for others (e.g., tasty food and sexually arousing stimuli).

Third, our study spanned 2 years. Therefore, the baselines of finances and well-being may have been contaminated with problems that have persisted for the 2-year period but that were not participants' normal baselines. Concerning the effect of psychological distress on finances, chronic mental illnesses, such as a depression, can therefore not be excluded as an alternative explanation. Given the answering format of the measurement instrument we used (more or less complaints than usual), this seems plausible. However, considering the possibility that the baseline of financial problems for some farmers may have meant a long-lasting, unusually poor or good financial situation, it is even more remarkable that it did not predict well-being.

In addition, the time interval between measurement moments was 1 year. It is interesting to note that a dynamic equilibrium exists over such a long period of time. Moreover, previous studies have shown stable levels of psychological distress to be of similar magnitude at 4 months, 6 months, 1 year, and irregular intervals of 1 to 7 years (Duncan-Jones et al., 1990; Ormel \& Schaufeli, 1991). However, in particular for well-being, these intervals are too long to capture the process of restoring the equilibrium. Recovery may typically be rather quick. To our knowledge, no studies using the stability-and-change model have used shorter intervals than 4 months. A next interesting study might focus on short-term changes and recovery, for example, by using daily measures of stressors and strains or using short-term measures in addition to long-term measures.

Fourth, our study did not contain specific information on homeostatic processes explaining the existence of traitlike baseline resource levels. It would be 
interesting to gain more insight into these internal processes, especially from a long-term perspective. Personality variables are likely to play an important role, given the strong correlations that previous studies have found between stable levels of well-being and traits, such as neuroticism, self-esteem, and locus of control (e.g., Duncan-Jones et al., 1990; Ormel \& Schaufeli, 1991). More insight is needed into the top-down mechanisms explaining these relationships. Focusing on cognitive processes underlying people's judgments of resource levels seems a promising area, for example, individual personality-related differences in accessibility of stable relevant cues (Schimmack, Diener, \& Oishi, 2002).

Finally, our study addressed a specific subsample of the Dutch population (farmers, most of whom were male). This begs the question to what extent our results can be generalized, particularly to employees on payroll or self-employed women. It would also be interesting to test the robustness of the model among samples operating in different objective environments, such as samples facing more severe, acute health threats compared with those facing few such threats, or samples confronted with many financial uncertainties compared with samples operating in a stable financial climate.

\section{Theoretical and Practical Implications}

Despite its limitations, our study provides valuable insights into the stress process by comprehensively integrating several complex mechanisms into one model, which up until now had only been studied in a fragmented and piecemeal fashion. This model can distinguish different kinds of resources based on the extent to which they have stable baseline levels. Additionally, it reveals how baseline and variable levels of different resources are related.

Ample evidence has shown that an emphasis on resources in stress research is broadly generalizable across different populations and levels of stress (e.g., Freedy \& Hobfoll, 1994; Freedy et al., 1994; Hobfoll et al., 2003; Holahan et al., 1999, 2000; King et al., 1998; Norris \& Kaniasty, 1996). The most important theoretical implication of our findings is that two different processes have been revealed that link resources to other resources. The first process represents the direct stress chain, in which resources are invested (and lost) to counteract stressors. The second is a management process moderating this direct stress chain, showing that key resources may help a person counteract resource loss when confronted with external demands (see Hobfoll, 2002). In COR theory, this latter, management process is yet to receive attention. It is tempting to conclude that the stable components of resources, such as the traitlike baseline of well-being, or more generally, stable personality resources, act as key resources, as this would be consistent with resource theories in cognitive psychology and human development and education (see Freund \& Riediger, 2001). This would mean another important influence of personality, in addition to maintaining baseline levels. However, as we addressed only two types of resources, this possibility remains speculative. After all, it is not unlikely that resources that often function as key resources, such as psychosocial resources, may be finite as well (Holahan et al., 1999). Distinguishing between traitlike baselines and statelike variable levels of key resources may therefore be equally important.

As for practical implications, this study shows that good mental health is a key factor to success. This justifies striving for good stable mental health. This study shows that for self-employed individuals, finances and mental health influence each other in a mutual way. Improving the financial situation helps them to feel better. However, reducing mental distress caused by financial problems will not automatically cause them to be better able to manage their finances. Unfortunately, for this reversed effect, a stable good mental health condition was found to be the active ingredient, which can only be influenced by using long-term processes of social and personal change and not by reducing short-term stressors.

$$
\mathrm{SI}_{\mathrm{T} 2}=\mathrm{B}_{2} * \mathrm{FP}_{\mathrm{T} 2}+\mathrm{B}_{1} *\left(\mathrm{FP}_{\mathrm{T} 2}-\mathrm{FP}_{\mathrm{T} 1}\right)+\varepsilon_{\mathrm{SI}},
$$

where $\varepsilon_{\mathrm{SI}}$ is the error term of health complaints. Note that if $B_{1}$ is positive, an increase in financial problems between $\mathrm{T} 1$ and $\mathrm{T} 2$ relates to more health complaints at T2. Equation 1 is equivalent to Equation 1a:

$$
\begin{aligned}
\mathrm{SI}_{\mathrm{T} 2} & =\mathrm{B}_{2} * \mathrm{FP}_{\mathrm{T} 2}+\mathrm{B}_{1} * \mathrm{FP}_{\mathrm{T} 2}-\mathrm{B}_{1} * \mathrm{FP}_{\mathrm{T} 1}+\varepsilon_{\mathrm{SI}} \\
& =\left(\mathrm{B}_{2}+\mathrm{B}_{1}\right) * \mathrm{FP}_{\mathrm{T} 2}-\mathrm{B}_{1} *\left(\mathrm{FP}_{\mathrm{T} 1}\right)+\varepsilon_{\mathrm{SI}}
\end{aligned}
$$

In other words, if the effect of the change variable $\left(\mathrm{FP}_{\mathrm{T} 2}-\mathrm{FP}_{\mathrm{T} 1}\right)$ is significant, this shows up as a suppressor effect: (a) Adding the relationship $\mathrm{B}_{1}$ to the model seemingly leads to an increase of the cross-sectional effect $\left(\mathrm{B}_{2}+\mathrm{B}_{1}\right)$ of financial problems on health complaints at $\mathrm{T} 2$, whereas (b) the sign of the causal effect $\mathrm{B}_{1}$ of financial problems at one point in time (T1) on health complaints at the next measurement moment (T2) will be in the opposite direction (and opposite to the first-order correlation between these two variables). To test whether only a 
changing financial situation leads to health complaints, $\mathrm{B}_{1}$ can be constrained to be zero, by constraining the cross-sectional relationship between finances and health $\left(B_{2}+B_{1}\right)$ to equal the relationship between finances and health over time, but with the opposite sign $\left(-\mathrm{B}_{1}\right)$.

\section{References}

Aldwin, C. M., \& Revenson, T. A. (1986). Vulnerability to economic stress. American Journal of Community Psychology, 14, 161-175.

Anderson, J. C., \& Gerbing, D. W. (1988). Structural equation modeling in practice: A review and recommended two-step approach. Psychological Bulletin, 3, 411-423.

Arata, C. M., Picou, J. S., Johnson, G. D., \& McNally, T. S. (2000). Coping with technological disaster: An application of the conservation of resources model to the Exxon Valdez oil spill. Journal of Traumatic Stress, 13, 23-39.

Arbuckle, J. L. (1997). AMOS 4.0 user's guide. Chicago: Smallwaters Corporation.

Baron, R. A. (1990). Environmentally induced positive affect: Its impact on self-efficacy, task performance, negotiation, and conflict. Journal of Applied Social Psychology, 20, 368-384

Beehr, T. A., Jex, S. M., Stacy, B. A., \& Murray, M. A. (2000). Work stressors and coworker support as predictors of individual strain and job performance. Journal of Organizational Behavior, 21, 391-405.

Bernard, L. C., \& Krupat, E. (1994). Health psychology, biopsychosocial factors in health and illness. Orlando, FL: Harcourt Brace College.

Brickman, P., Coates, D., \& Janoff-Bulman, R. (1978). Lottery winners and accident victims: Is happiness relative? Journal of Personality and Social Psychology, 36, 917-927.

Burke, M. J., Brief, A. P., \& George, J. M. (1993). The role of negative affectivity in understanding relations between self-reports of stressors and strains: A comment on the applied psychology literature. Journal of Applied Psychology, 78, 402-412.

Clark, A. (1998). Are wages habit forming? Evidence from micro-data. Journal of Economic Behavior and Organization, 39, 179-200.

Cummins, R. A. (2000). Objective and subjective quality of life: An interactive model. Social Indicators Research, $52,55-72$.

Cummins, R. A., \& Nistico, H. (2002). Maintaining life satisfaction: The role of positive cognitive bias. Journal of Happiness Studies, 3, 37-69.

Depue, R. A., \& Monroe, S. M. (1985). Life stress and human disorder: Conceptualisation and measurement of the disordered group. In I. G. Sarason \& B. R. Sarason (Eds.), Social support: Theory, research and applications (pp. 303-324). Dordrecht, the Netherlands: Martinus Nijhoff.

Diener, E. (2000). Subjective well-being: The science of happiness and a proposal for a national index. American Psychologist, 55, 34-43.

Diener, E., Suh, E. M., Lucas, R. E., \& Smith, H. L. (1999). Subjective well-being: Three decades of progress. Psychological Bulletin, 125, 276-302.
Dirken, J. M. (1967). Het meten van stress in industriële situaties: Een multidisciplinaire ontwikkeling van een algemeen diagnosticum [Measuring stress in industrial environments: A multidisciplinary development of a general measurement instrument.]. Groningen, the Netherlands: Wolters.

Duncan-Jones, P., Fergusson, D. M., Ormel, J. O., \& Horwood, L. J. (1990). A model of stability and change in minor psychiatric symptoms: Results from three longitudinal studies. Psychological Medicine (Monograph Suppl.), 18, 3-28.

Ennis, N., Hobfoll, S. E., \& Schröder, K. E. E. (2000). Money doesn't talk, it swears: How economic stress and resistance impact inner-city women's depressive mood. American Journal of Community Psychology, 28, 149173.

Fergusson, D. M., \& Horwood, L. J. (1988). Structural equation modelling of measurement processes in longitudinal data. In M. Rutter (Ed.), Studies of psychological risk: The power of longitudinal data (pp. 325-353). Cambridge, England: Cambridge University Press.

Frederick, S., \& Loewenstein, G. (1999). Hedonic adaptation. In N. Schwarz (Ed.), Well-being: The foundations of hedonic psychology (pp. 302-329). New York: Russell Sage Foundation.

Freedy, J. R., \& Hobfoll, S. E. (1994). Stress inoculation for reduction of burnout: A conservation of resources approach. Anxiety, Stress, and Coping, 6, 311-325.

Freedy, J. R., Saladin, M. E., Kilpatrick, D. G., Resnick, H. S., \& Saunders, B. E. (1994). Understanding acute psychological distress following natural disaster. Journal of Traumatic Stress, 7, 257-273.

Freund, A. M., \& Riediger, M. (2001). What I have and what I do: The role of resource loss and resource gain throughout life. Journal of Applied Psychology, 50, 370380 .

Gallagher, A. G., \& Tierney, K. (1996). The impact of the environment on physical and mental health. Irish Journal of Psychology, 17, 361-372.

Gasson, R., \& Errington, A. (1993). The farm family business. Wallingford, England: $\mathrm{CAB}$ International.

Giesen, C. W. M. (1991). Werkverhoudingen en stress op het boerenbedrijf [Stress and work issues among farm couples]. Amsterdam: Thesis Publishers.

Glickman, L., Tanaka, J. S., \& Chan, E. (1991). Life events, chronic strain, and psychological distress: Longitudinal causal models. Journal of Community Psychology, 19, 283-305.

Goldberg, D. P. (1972). The detection of psychiatric illness by questionnaire. London: Oxford University Press.

Gorgievski-Duijvesteijn, M. J. (1999). Job-involvement and stress in farm-couples. Gedrag en Gezondheid, 27, 109117.

Gorgievski-Duijvesteijn, M. J., Giesen, C. W. M., \& Bakker, A. B. (2000). Financial problems and health complaints among farm couples: Results of a 10-year follow-up study. Journal of Occupational Health Psychology, 5, 359-373.

Hamilton, V. L., Hoffman, W. S., Broman, C. L., \& Rauma, D. (1993). Unemployment, distress and coping: A panel study of autoworkers. Journal of Personality and Social Psychology, 65, 234-247.

Heady, B., \& Wearing, A. (1989). Personality, life events, and subjective well-being: Towards a dynamic equilib- 
rium model. Journal of Personality and Social Psychology, 57, 731-739.

Hobfoll, S. E. (1988). The ecology of stress. Washington, DC: Hemisphere.

Hobfoll, S. E. (1989). Conservation of resources, a new attempt at conceptualizing stress. American Psychologist, 44, 513-524.

Hobfoll, S. E. (1998). Stress, culture and community. The psychology and philosophy of stress. New York: Plenum Press.

Hobfoll, S. E. (2001). The influence of culture, community and the nested-self in the stress process: Advancing conservation of resources theory. Journal of Applied Psychology, 50, 337-396.

Hobfoll, S. E. (2002). Social and psychological resources and adaptation. Review of General Psychology, 6, 307324.

Hobfoll, S. E., Johnson, R. J., Ennis, N., \& Jackson, A. P. (2003). Resource loss, resource gain, and emotional outcomes among inner city women. Journal of Personality and Social Psychology, 84, 632-643.

Holahan, C. J., Holahan, C. K., Moos, R. H., \& Cronkite, R. C. (2000). Long-term post treatment functioning among patients with unipolar depression: An integrative model. Journal of Consulting and Clinical Psychology, $68,226-232$.

Holahan, C. J., Moos, R. H., Holahan, C. K., \& Cronkite, R. C. (1999). Resource loss, resource gain and depressive symptoms: A 10-year model. Journal of Personality and Social Psychology, 77, 620-629.

Hu, L., \& Bentler, P. M. (1999). Cutoff criteria for fit indices in covariance structure analysis: Conventional criteria versus new alternatives. Structural Equation Modeling, 6, 1-55.

Jex, S. M. (1998). Stress and job performance: Theory, research and implications for managerial practice. London: Sage.

Jones, F., \& Fletcher, B. C. (1993). An empirical study of occupational stress transmission in working couples. $\mathrm{Hu}$ man Relations, 46, 881-903.

Jonge, J. d., Dormann, C., Janssen, P. P. M., Dollard, M. F., Landeweerd, J. A., \& Nijhuis, F. J. (2001). Testing reciprocal relationships between job characteristics and psychological well-being: A cross-lagged structural equation model. Journal of Occupational and Organizational Psychology, 74, 29-46.

King, L. A., King, D. W., Keane, T. M., Fairbank, J. A., \& Adams, G. A. (1998). Resilience-recovery factors in post-traumatic stress disorder among female and male Vietnam veterans: Hardiness, postwar social support, and additional stressful life events. Journal of Personality and Social Psychology, 74, 420-434.

Kozma, A., Stone, S., \& Stones, M. J. (2000). Stability in components and predictors of subjective well-being (SWB): Implications for SWB structure. In E. Diener \& D. R. Rahtz (Eds.), Advances in quality of life theory and research (pp. 13-30). Dordrecht, the Netherlands: Kluwer Academic.

Landbouw Economisch Instituut. (2000). Landbouw economisch bericht [Agricultural economic report]. Den Haag, the Netherlands: Landbouw Economisch Instituut.

Lorenz, F. O., Conger, R. D., Montague, R. B., \& Wickrama, K. A. S. (1993). Economic conditions, spouse support, and psychological distress of rural husbands and wives. Rural Sociology, 58, 247-268.

Lovallo, W. R. (1997). Stress and health: Biological and psychological interactions. London: Sage.

Motowidlo, S. J., Manning, M. R., \& Packard, J. S. (1986). Occupational stress: Its causes and consequences for job performance. Journal of Applied Psychology, 71, 618629.

Mulder, M. (1994). Bedrijfstakverkenning en financiële analyse; een simulatiemodel voor de glastuinbouw [Sector exploration and financial analysis: A simulation model for horticulture under glass.] (Report No. 126). The Hague, the Netherlands: Landbouw Economisch Instituut.

Norris, F. H., \& Kaniasty, K. (1996). Received and perceived social support in times of stress: A test of the social support deterioration deterrence model. Journal of Personality and Social Psychology, 71, 498-511.

Ormel, J. O., \& Schaufeli, W. B. (1991). Stability and change in psychological distress and their relationship with self esteem and locus of control: A dynamic equilibrium model. Journal of Personality and Social Psychology, 60, 288-299.

Ormel, J. O., \& Wohlfahrt, T. (1991). How neuroticism, long-term difficulties, and life situation change influence psychological distress: A longitudinal model. Journal of Personality and Social Psychology, 60, 744-755.

Pearlin, L. I., Lieberman, M. A., Menaghan, E. G., \& Mullan, J. T. (1981). The stress process. Journal of Health and Social Behavior, 22, 337-356.

Rosenblatt, P. C. (1990). Farming is in our blood. Farm families in economic crisis. Ames: Iowa State University Press.

Saris, W. E. (2001). The relationship between income and satisfaction: The effect of measurement error and suppressor variables. Social Indicators Research, 53, 117136.

Schaufeli, W. B. (1997). Youth unemployment and mental health: Some Dutch findings. Journal of Adolescence, 20, 281-292.

Schimmack, U., Diener, E., \& Oishi, S. (2002). Life-satisfaction is a momentary judgment and a stable personality characteristic: The use of chronically accessible and stable sources. Journal of Personality, 70, 345-384.

Statistics Netherlands. (2000). Enquête beroepsbevolking [Survey labor force]. Heerlen, the Netherlands: Centraal Bureau voor de Statistiek.

Staw, B. M., Sandelands, L. E., \& Dutton, J. E. (1981). Threat rigidity effects in organizational behavior: A multilevel analysis. Administrative Science Quarterly, 26, 501-524.

Stones, M. J., Hadjistavropoulos, T., Tuuko, H., \& Kozma, A. (1995). Happiness has trait-like and state-like properties: A reply to Veenhoven. Social Indicators Research, 36, 129-144.

Suh, E. M., Diener, E., \& Fujita, F. (1996). Events and subjective well-being: Only recent events matter. Journal of Personality and Social Psychology, 70, 1091-1102.

Swisher, R. R., Elder, G. H., Lorenz, F. O., \& Conger, R. D. (1998). The long arm of the farm: How occupation structures exposure and vulnerability to stressors across role domains. Journal of Health and Social Behavior, 39, 72-89.

Taris, T. W. (1999). The mutual effects between job-re- 
sources and mental health: A prospective study among Dutch youth. Genetic, Social and General Psychology Monographs, 125, 433-450.

Taris, T. W., Bok, I. A., \& Caljé, D. G. (1998). On the relation between job-characteristics and depression: A longitudinal study. International Journal of Stress Management, 5, 157-167.

Taylor, S. E., \& Brown, J. D. (1988). Illusion and wellbeing: A social psychological perspective on mental health. Psychological Bulletin, 103, 193-210.

Taylor, S. E., \& Brown, J. D. (1994). Positive illusions and well-being revisited: Separating fact from fiction. Psychological Bulletin, 116, 21-27.

Trope, Y., \& Neter, E. (1994). Reconciling competing motives in self-evaluation: The role of self-control in feedback seeking. Journal of Personality and Social Psychology, 66, 646-657.

Van Dijk, J. P. M., Groot, J. J. P., Lodder, K., \& Vrolijk, H. C. J. (1998). De steekproef voor het bedrijven informatienet van het LEI: Bedrijfskeuze 1999 en selectieplan 2000. [The sample for the Farm Accountancy Data Network: Choice of businesses 1999 and plan of selection 2000.]. The Hague, the Netherlands: Landbouw Economisch Instituut.
Van Horn, J. E., Taris, T. W., Schaufeli, W. B., \& Schreurs, P. J. G. (2004). The structure of occupational well-being: A study among Dutch teachers. Journal of Occupational and Organizational Psychology, 77, 365-375.

Vidal, C. (2000). Thirty years of agriculture in Europe: Farm numbers decline as farms grow in size. Statistics in Focus, 5, 1-7.

Vinokur, A. D., Price, R. H., \& Caplan, R. D. (1996). Hard times and hurtful partners: How financial strain affects depression and relationship satisfaction of unemployed persons and their spouses. Journal of Personality and Social Psychology, 71, 166-179.

Watson, D., \& Pennebaker, J. W. (1989). Health complaints, stress, and distress: Exploring the central role of negative affectivity. Psychological Review, 96, 234-254.

Zapf, D., Dormann, C., \& Frese, M. (1996). Longitudinal studies in organizational stress research: A review of the literature with reference to methodological issues. Journal of Occupational Health Psychology, 1, 145-169.

Received May 7, 2003

Revision received July 2, 2004 Accepted September 6, 2004 